\title{
Gambaran kelainan katup jantung pada pasien infark miokard di RSUP Prof. Dr. R. D. Kandou Manado periode 1 Januari 2015-31 Desember 2015
}

\author{
${ }^{1}$ Mawarni I. S. Tumbel \\ ${ }^{2}$ Agnes L. Panda \\ ${ }^{2}$ Janry Pangemanan
}

\author{
${ }^{1}$ Kandidat Skripsi Fakultas Kedokteran Universitas Sam Ratulangi Manado \\ ${ }^{2}$ Bagian Kardiologi Fakultas Kedokteran Universitas Sam Ratulangi Manado \\ Email: tumbelsari@gmail.com
}

\begin{abstract}
Myocardial infarction is divided into STEMI (ST elevation myocardial infarction) and NSTEMI (Non ST elevation myocardial Infarction). According to location, infarction consists of inferior, lateral, and aortal. Inferior infarction often causes mitral valve and aortal abnormality due to papillary muscles rupture. This study was aimed to obtain the description of heart valve abnormality in myocardial infarction patients at Prof. Dr. R. D Kandou Hospital Manado from January 2015 to December 2015. This was a retrospective study with a cross sectional design. The results showed that there were 20 cases $(90.9 \%)$ of NSTEMI and 2 cases $(9.1 \%)$ of STEMI. The most location of infarction was inferior accounted for 10 cases $(45.5 \%)$. The most heart valve abnormalities were combination abnormality accounted for 16 cases (72.7\%); most were mild MR (5 cases; 55.6\%), mild PR (5 cases; 55.6\%), and mild TR ( 3 cases; $33.3 \%$ ) in NSTEMI cases dominated by male cases $(54.5 \%)$ and age group 56-66 years (40.9\%), and combination of 4 major risk factors $(59.1 \%)$.
\end{abstract}

Keywords: description, heart valve abnormality, myocardial infarction

\begin{abstract}
Abstrak: Infark miokard terbagi menjadi STEMI (ST elevation myocardial infarction) dan NSTEMI (Non ST elevation myocardial infarction). Infark berdasarkan lokasi terdiri atas inferior, lateral, anterior dan aorta. Infark inferior sering menyebabkan kelainan katup mitral dan aorta akibat ruptur muskulus papilaris. Penelitian ini bertujuan untuk mengetahui gambaran kelainan katup jantung pada pasien infark miokard di RSUP Prof. Dr. R. D. Kandou Manado periode 1 Januari 2015 - 31 Desember 2015. Jenis penelitian ialah retrospektif dengan desain potong lintang. Hasil penelitian mendapatkan 20 kasus $(90,9 \%)$ NSTEMI dan 2 kasus $(9,1 \%)$ STEMI. Lokasi infark terbanyak yaitu inferior sebanyak 10 kasus (45,5\%), didapati kelainan katup terbanyak yaitu kombinasi sebanyak 16 kasus (72,7\%), dengan derajat terbanyak yaitu MR mild 5 kasus (55,6\%), PR mild 5 kasus (55,6\%) dan TR mild sebanyak 3 kasus $(33,3 \%)$ pada pasien NSTEMI, yang didominasi oleh pasien laki-laki $(54,5 \%)$, usia $56-66$ tahun $(40,9 \%)$, yang memiliki 4 faktor resiko mayor $(59,1 \%)$.

Kata kunci: gambaran, kelainan katup, infark miokard.
\end{abstract}

Infark miokard umumnya dikenal sebagai serangan jantung atau dapat didefinisikan sebagai kematian sel miokard yang irreversible akibat iskemia berkepanjangan. Iskemia terjadi ketika salah satu arteri koroner tersumbat baik secara total maupun parsial. $^{1}$ Proses penyumbatan ini di awali oleh plak ateroskleorosis yang ruptur (pecah). Hal ini berkaitan dengan perubahan komposisi plak dan lapisan fibrus yang menutupi plak tersebut. Kejadian ini diikuti oleh proses agregasi 
trombosit dan aktivasi jalur koagulasi sehingga terbentuklah trombus yang kaya akan trombosit. ${ }^{1}$ Trombus inilah yang menjadi mikroemboli sehingga menyumbat liang pembuluh darah koroner yang lebih distal. Infark miokard menyebabkan komplikasi mekanik yang dapat berujung pada kelainan-kelainan atau disfungsi katup jantung. Dalam hal ini regurgitasi katup jantung. ${ }^{2}$ Angka kejadian tersering adalah Regurgitasi katup mitral. Hal ini disebabkan oleh adanya STEMI inferior dan anterior yang menyebabkan ruptur muskulus papilaris yang berujung pada dilatasi annulus sehingga menyebabkan regurgitasi katup mitral. Direktorat Jenderal Yanmedik Indonesia meneliti, bahwa pada tahun 2007, jumlah pasien penyakit jantung yang menjalani rawat inap dan rawat jalan di rumah sakit di Indonesia ialah 239.548 orang. Kasus terbanyak adalah penyakit jantung iskemik, yaitu sekitar 110.183 kasus. Case fatality Rate (CFR) tertinggi terjadi pada infark miokard akut $(13,49 \%)$ dan kemudian diikuti oleh gagal jantung $(13,42 \%)$. Sekitar 1,5 juta kasus infark miokard (MI) terjadi setiap tahun di Amerika Serikat; tingkat kejadian tahunan adalah sekitar 600 kasus per 100.000 orang. ${ }^{3}$ Menurut laporan WHO, pada tahun 2004, penyakit infark miokard akut merupakan penyebab kematian utama di dunia. Sebanyak 7,2 juta (12,2\%) kematian terjadi akibat penyakit ini diseluruh dunia. Infark miokard akut merupakan penyebab kematian nomor dua pada negara berpenghasilan rendah, dengan angka mortalitas 2,47 juta $(9,4 \%)$. Di Indonesia pada tahun 2002, penyakit infark miokard akut merupakan penyebab kematian pertama, dengan angka mortalitas 220.000 $(14 \%)^{3}$

Beberapa penelitian menyebutkan infark miokard dapat menyebabkan komplikasi pada katup jantung. ${ }^{4,5}$ Begitu juga sebaliknya, kelainan katup jantung dapat berujung pada kejadian infark miokard. ${ }^{4}$ Berdasarkan data-data yang telah disebutkan, penulis merasa tertarik untuk mengetahui gambaran kelainan katup jantung pada pasien infark miokard.

\section{METODE PENELITIAN}

Jenis penelitian ini ialah deskriptif retrospektif dengan cara mengumpulkan data rekam medis pasien Infark (STEMI NSTEMI) yang mengalami kelainan katup jantung di RSUP Prof. Dr. R. D. Kandou. Sampel penelitian yaitu pasien infark miokard yang mengalami kelainan katup jantung yang tercatat dalam catatan rekam medik di CVBC RSUP Prof. R. D. Kandou Manado periode 1 Januari 2015-31 Desember 2015.

\section{HASIL PENELITIAN}

Dari total 38 pasien infark miokard (STEMI dan NSTEMI) hanya 22 pasien yang memenuhi kriteria inklusi (Tabel 1).

\section{Distribusi Pasien STEMI dan NSTEMI dengan Kelainan Katup Jantung}

Dari hasil penelitian, dari 22 pasien infark miokard didapatkan 2 orang $(9,1 \%)$ pada pasien STEMI dan sebanyak 20 orang $(90,9 \%)$ pada pasien NSTEMI (Tabel 2).

\section{Distribusi Pasien Infark Miokard dengan Kelainan Katup Jantung Berdasarkan Jenis Kelamin \\ Dari hasil penelitian, pasien dengan kelompok jenis kelamin laki-laki sebanyak 12 orang (54\%) dan kelompok jenis kelamin perempuan sebanyak 10 orang $(45,5 \%)$ (Tabel 3).}

\section{Distribusi Pasien Infark Miokard dengan Kelainan Katup Jantung Berdasarkan Kelompok Usia. \\ Dari hasil penelitian, didapatkan data} jumlah sampel dengan kelompok usia 4555 tahun sebanyak 5 orang $(22,7 \%)$, kelompok usia 56-66 tahun sebanyak 9 orang $(40,9 \%)$, kelompok usia 67-75 tahun sebanyak 6 orang $(27,3 \%)$, dan kelompok usia $>75$ tahun sebanyak 2 orang $(9,1 \%)$. (Tabel 4). 
Tabel 1. Data Karakteristik dasar

\begin{tabular}{|c|c|c|c|}
\hline \multirow[b]{2}{*}{ Karakteristik } & \multicolumn{3}{|c|}{$\begin{array}{l}\text { Kelainan Katup Jantung Pada Pasien } \\
\text { Infark Miokard }\end{array}$} \\
\hline & $\begin{array}{c}\text { STEMI } \\
(\mathrm{n}=2)\end{array}$ & $\begin{array}{l}\text { NSTEMI } \\
(\mathbf{n}=20)\end{array}$ & $\begin{array}{l}\text { Jumlah } \\
(\mathrm{n}=22)\end{array}$ \\
\hline \multicolumn{4}{|l|}{ Jenis Kelamin } \\
\hline laki-laki & $1(50 \%)$ & $11(55 \%)$ & $12(54,5 \%)$ \\
\hline Perempuan & $1(50 \%)$ & $9(45 \%)$ & $10(45,5 \%)$ \\
\hline \multicolumn{4}{|l|}{ Usia (tahun) } \\
\hline $45-55$ & $0(0 \%)$ & $5(25 \%)$ & $5(25 \%)$ \\
\hline $56-66$ & $2(100 \%)$ & $7(35 \%)$ & $9(40,9 \%)$ \\
\hline $67-75$ & $0(0 \%)$ & $6(30 \%)$ & $6(27,3 \%)$ \\
\hline$>75$ & $0(0 \%)$ & $2(10 \%)$ & $2(9,1 \%)$ \\
\hline \multicolumn{4}{|l|}{$\begin{array}{l}\text { Faktor Resiko } \\
\text { PJK }\end{array}$} \\
\hline $\begin{array}{l}\text { Hipertensi } \\
\text { Diabetes }\end{array}$ & $0(0 \%)$ & $4(20 \%)$ & $4(18,2 \%)$ \\
\hline mellitus & $0(0 \%)$ & $0(0 \%)$ & $0(0 \%)$ \\
\hline Dislipidemia & $0(0 \%)$ & $2(10 \%)$ & $2(9,1 \%)$ \\
\hline Merokok & $0(0 \%)$ & $0(0 \%)$ & $0(0 \%)$ \\
\hline Kombinasi & $2(100 \%)$ & $11(55 \%)$ & $13(59 \%)$ \\
\hline $\begin{array}{l}\text { tidak ada resiko } \\
\text { mayor }\end{array}$ & $0(0 \%)$ & $3(15 \%)$ & $3(13,6 \%)$ \\
\hline $\begin{array}{c}\text { Ekokardiografi } \\
\text { LVEF } \geq 54 \%\end{array}$ & $1(50 \%)$ & $7(35 \%)$ & $8(36.4 \%)$ \\
\hline $40-53 \%$ & $1(50 \%)$ & $3(15 \%)$ & $4(18,2 \%)$ \\
\hline$\leq 40 \%$ & $0(0 \%)$ & $10(50 \%)$ & $10(45,5 \%)$ \\
\hline
\end{tabular}

LVEF: Left Ventricular Ejection Fraction, STEMI: ST Elevation Myocardia Infarction, NSTEMI; Non ST Elevation Myocardial Infarction

Tabel 2. Distribusi sampel berdasarkan pasien infark miokard

\begin{tabular}{ccc}
\hline Infark Miokard & $(\mathbf{n = 2 2})$ & $\mathbf{( \% )}$ \\
\hline STEMI & 2 & $9,1 \%$ \\
NSTEMI & 20 & $90,9 \%$ \\
\hline
\end{tabular}

Tabel 3. Distribusi Sampel Berdasarkan Kelompok Jenis Kelamin

\begin{tabular}{ccc}
\hline Jenis Kelamin & $(\mathbf{n = 2 2})$ & $\mathbf{( \% )}$ \\
\hline Laki-laki & 12 & $54,5 \%$ \\
Perempuan & 10 & $45,5 \%$ \\
\hline
\end{tabular}

Tabel 4. Distribusi Sampel Berdasarkan Kelompok Usia.

\begin{tabular}{ccc}
\hline Usia (tahun) & $\mathbf{( n = 2 2 )}$ & $\mathbf{( \% )}$ \\
\hline $45-55$ & 5 & $22,7 \%$ \\
$56-66$ & 9 & $40,9 \%$ \\
$67-75$ & 6 & $27,3 \%$ \\
$>75$ & 2 & $9,1 \%$ \\
\hline
\end{tabular}

Distribusi Pasien Infark Miokard dengan Kelainan Katup Jantung Berdasarkan Faktor Resiko

Dari hasil penelitian, sampel memiliki riwayat hipertensi sebanyak 4 orang $(18,2 \%), 2$ orang $(9,1 \%)$ dengan riwayat dyslipidemia, 13 orang $(59,1 \%)$ dengan riwayat faktor resiko kombinasi, dan 3 orang $(13,6 \%)$ tidak memiliki resiko mayor; tidak didapatkan riwayat diabetes melitus dan merokok (Tabel 5).

\section{Distribusi Pasien Infark Miokard} dengan Kelainan Katup Jantung Berdasarkan Nilai Fraksi Ejeksi

Dari hasil penelitian, jumlah sampel dengan nilai fraksi ejeksi $\geq 54$ berjumlah 8 orang $(36,4 \%)$ dan nilai fraksi ejeksi 40-53 sebanyak 4 orang $(18,2 \%)$. Sebanyak 10 orang $(45,5 \%)$ dengan nilai fraksi ejeksi $\leq 40$ (Tabel 6). 
Tumbel, Panda, Pangemanan: Gambaran kelainan katup...

Tabel 5. Distribusi Sampel Berdasarkan Faktor Resiko

\begin{tabular}{ccc}
\hline Faktor Resiko & $(\mathbf{n = 2 2})$ & $\mathbf{( \% )}$ \\
\hline Hipertensi & 4 & $18,2 \%$ \\
Diabetes Melitus & 0 & $0 \%$ \\
Dislipidemia & 2 & $9,1 \%$ \\
Merokok & 0 & $0 \%$ \\
Kombinasi & 13 & $59,1 \%$ \\
Tidak ada resiko mayor & 3 & $13,6 \%$ \\
\hline
\end{tabular}

Tabel 6. Distribusi Sampel Berdasarkan Nilai Fraksi Ejeksi

\begin{tabular}{ccc}
\hline $\begin{array}{c}\text { Fraksi } \\
\text { Ejeksi (\%) }\end{array}$ & $(\mathbf{n = 2 2 )}$ & $(\boldsymbol{\%})$ \\
\hline$\geq 54$ & 8 & $36,4 \%$ \\
$40-53$ & 4 & $18,2 \%$ \\
$\leq 40$ & 10 & $45,5 \%$ \\
\hline
\end{tabular}

\section{Distribusi Pasien Infark Miokard dengan Kelainan Katup Jantung Berdasarkan Lokasi Infark \\ Dari hasil penelitian, jumlah sampel dengan lokasi infark anterior sebanyak 9 orang $(40,9 \%)$, lokasi Inferior sebanyak 10 orang $(45,5 \%)$, lokasi lateral sebanyak 3 orang $(13,6 \%)$, dan kombinasi (Inferior+ RV) sebanyak 1 orang (4,5\%) (Tabel 7).}

Tabel 7. Distribusi Sampel Berdasarkan Lokasi Infark Miokard

\begin{tabular}{ccc}
\hline $\begin{array}{c}\text { Lokasi } \\
\text { Infark }\end{array}$ & $(\mathbf{n = 2 2 )}$ & $(\boldsymbol{\%})$ \\
\hline Anterior & 9 & $40,9 \%$ \\
Inferior & 10 & $45,5 \%$ \\
Lateral & 3 & $13,6 \%$ \\
Kombinasi & 1 & $4,5 \%$ \\
\hline
\end{tabular}

Distribusi Jenis Kelainan Katup Berdasarkan Lokasi Infark Pada Pasien NSTEMI

Dari hasil penelitian, didapatkan kelainan katup MR pada infark anterior sebanyak 3 orang (37,5\%), tidak didapatkan MR pada infark inferior, lateral dan kombinasi (InferiorRV). Tidak didapatkan AR pada infark anterior, inferior, dan lateral. Ada 1 orang (100\%) mengalami AR pada infark kombinasi (inferior RV). Pada infark anterior didapatkan sebanyak 4 orang (50\%) dengan kelainan katup kombinasi, 7 orang $(87,5 \%)$ pada infark inferior, 3 orang $(100 \%)$ pada infark lateral. (Tabel 8).

Tabel 8. Distribusi sampel berdasarkan kelainan katup dan lokasi infark

\begin{tabular}{ccccc}
\hline & & \multicolumn{2}{c}{$\begin{array}{c}\text { lokasi Infark } \\
\text { Lateral } \\
(\mathbf{n = 3})\end{array}$} & $\begin{array}{c}\text { Kombinasi } \\
(\text { Inferior+RV) } \mathbf{n}=\mathbf{1}\end{array}$ \\
\hline Melainan Katup & Anterior $(\mathbf{n = 7})$ & $(\mathbf{n = 9})$ & $0(0 \%)$ & $0(0 \%)$ \\
AR & $3(37,5 \%)$ & $0(0 \%)$ & $0(0 \%)$ & $1(100 \%)$ \\
TR & $0(0 \%)$ & $0(0 \%)$ & $0(0 \%)$ & $0(0 \%)$ \\
PR & $0(0 \%)$ & $0(0 \%)$ & $0(0 \%)$ & $0(0 \%)$ \\
Kombinasi & $0(0 \%)$ & $0(0 \%)$ & $3(100 \%)$ & $0(0 \%)$ \\
\hline
\end{tabular}

\section{Distribusi Jenis Kelainan Katup Berdasarkan Lokasi Infark Pada Pasien STEMI}

Dari hasil penelitian, didapatkan kelainan katup AR sebanyak 1 orang $(100 \%)$ pada infark inferior dan sebanyak 1 orang $(100 \%)$ dengan kelainan katup kombinasi pada infark anterior (Tabel 9).
Tabel 9. Distribusi sampel berdasarkan kelainan katup dan lokasi infark

\section{Lokasi Infark}

Kelainan

\begin{tabular}{lcc} 
Katup & $\begin{array}{c}\text { Anterior } \\
(\mathbf{n = 1})\end{array}$ & $\begin{array}{c}\text { Inferior } \\
(\mathbf{n}=\mathbf{1})\end{array}$ \\
\hline AR & $0(0 \%)$ & $1(100 \%)$ \\
Kombinasi & $1(100 \%)$ & $0(0 \%)$ \\
\hline
\end{tabular}


Tabel 10. Distribusi sampel berdasarka derajat beratnya kelaianan katup

\begin{tabular}{|c|c|c|c|}
\hline $\begin{array}{c}\text { Derajat Kelainan } \\
\text { Katup }\end{array}$ & $\begin{array}{c}\text { Anterior } \\
(\mathbf{n}=7)\end{array}$ & $\begin{array}{c}\text { okasi Infai } \\
\text { Inferior } \\
(\mathbf{n}=9)\end{array}$ & $\begin{array}{c}\text { Lateral } \\
(\mathbf{n}=\mathbf{3})\end{array}$ \\
\hline MR & $3(42,9 \%)$ & $0(0 \%)$ & $0(0 \%)$ \\
\hline Mild & $0(0 \%)$ & $0(0 \%)$ & $0(0 \%)$ \\
\hline Moderate & $0(0 \%)$ & $0(0 \%)$ & $0(0 \%)$ \\
\hline Severe & $0(0 \%)$ & $0(0 \%)$ & $0(0 \%)$ \\
\hline \multicolumn{4}{|l|}{ Kombinasi } \\
\hline \multicolumn{4}{|l|}{ MR } \\
\hline Mild & $2(28,6 \%)$ & $5(55,6 \%)$ & $0(0 \%)$ \\
\hline moderate & $2(28,6 \%)$ & $1(11,1 \%)$ & $3(100 \%)$ \\
\hline Severe & $1(14,3 \%)$ & $1(11,1 \%)$ & $0(0 \%)$ \\
\hline \multicolumn{4}{|l|}{ AR } \\
\hline mild & $3(42,9 \%)$ & $0(0 \%)$ & $3(100 \%)$ \\
\hline moderate & $1(14,3 \%)$ & $1(11,1 \%)$ & $0(0 \%)$ \\
\hline severe & $0(0 \%)$ & $0(0 \%)$ & $0(0 \%)$ \\
\hline \multicolumn{4}{|l|}{ TR } \\
\hline mild & $2(28,6 \%)$ & $3(33,3 \%)$ & $0(0 \%)$ \\
\hline moderate & $0(0 \%)$ & $2(22,2 \%)$ & $1(33,3 \%)$ \\
\hline severe & $1(14,3 \%)$ & $0(0 \%)$ & $0(0 \%)$ \\
\hline \multicolumn{4}{|l|}{ PR } \\
\hline mild & $3(42,9 \%)$ & $5(55,6 \%)$ & $2(66,7 \%)$ \\
\hline moderate & $1(14,3 \%)$ & $1(11,1 \%)$ & $0(0 \%)$ \\
\hline severe & $0(0 \%)$ & $0(0 \%)$ & $0 \quad(0 \%)$ \\
\hline
\end{tabular}

Distribusi Derajat Beratnya Kelainan Katup Berdasarkan Lokasi Infark Pada Pasien NSTEMI

Dari hasil penelitian, didapatkan MR mild sebanyak 3 orang $(42,8 \%)$ pada infark anterior. Pada infark anterior, didapatkan kelainan katup kombinasi dengan MR mild sebanyak 2 (28,6\%), MR moderate $2(28,6 \%)$, MR severe $1(14,3 \%)$. AR mild sebanyak 3 (42,9\%), AR moderate sebanyak $1(14,3 \%)$, AR severe tidak ada. TR mild sebanyak 2 ( $28,6 \%)$, TR moderate tidak ada (0\%), TR severe sebanyak $1(14,3$ $\%)$.

PR mild sebanyak 3 (42,9\%), PR moderate sebanyak 1 (14,3\%), dan PR severe tidak ada $(0 \%)$. Pada infark inferior, didapatkan kelainan katup kombinasi dengan MR mild sebanyak 5 (55,6\%), MR moderate sebanyak $1(11,1 \%)$, MR severe 1 $(11,1 \%)$ ada AR moderate sebanyak 1
$(11,1 \%)$, TR mild sebanyak $3(33,3 \%)$, TR moderate sebanyak 2 (22,2\%), PR mild sebanyak 5 (55,6\%), dan PR moderate sebanyak 1 (11,1\%). Pada infark lateral didapatkan, kelainan katup kombinasi yaitu MR moderate sebanyak 3 (100\%), AR mild sebanyak 3 (100\%), TR moderate sebanyak 1 (33,3\%), dan PR mild sebanyak 2 $(66,7 \%)$ (Tabel 11).

\section{Distribusi Derajat Beratnya Kelainan Katup Berdasarkan Lokasi Infark Pada Pasien STEMI}

Dari hasil penelitian, didapatkan AR moderate sebanyak 1 (100\%) pada infark inferior. Pada infark anterior, didapatkan kelainan katup kombinasi yaitu; mr mild sebanyak $1(100 \%)$, AR mild sebanyak 1 (100\%), PR mild sebanyak 1 (100\%). (Tabel 11). 
Tumbel, Panda, Pangemanan: Gambaran kelainan katup...

Tabel 11. Distribusi sampel berdasarkan derajat beratnya kelainan katup

\begin{tabular}{ccc}
\hline Derajat Kelainan Katup & Anterior $(\mathbf{n}=\mathbf{1})$ & Inferior $(\mathbf{n}=\mathbf{1})$ \\
\hline AR & - & - \\
mild & - & $1(100 \%)$ \\
moderate & - & - \\
severe & & - \\
KOMBINASI & $1(100 \%)$ & - \\
MR & - & - \\
mild & - & - \\
moderate & & - \\
severe & $1(100 \%)$ & - \\
AR & - & - \\
mild & - & - \\
moderate & & - \\
severe & $1(100 \%)$ & - \\
PR & - & - \\
mild & - & - \\
moderate & severe & .
\end{tabular}

Ket: AR (Aorta Regurgitasi), MR (Mitral Regurgitasi), AR (Aorta Regurgitasi), PR (Pulmonal Regurgitasi)

\section{BAHASAN}

Berdasarkan jenis infark, kejadian paling tinggi ialah NSTEMI sebanyak 20 orang $(20 \%)$ dan 2 orang $(9,1 \%)$ pasien STEMI. Hal ini sesuai dengan European Society of Cardiology Journal tahun 2012 mengatakan bahwa angka kejadian NSTEMI lebih sering dibandingkan dengan STEMI yang mengalami penurunan. ${ }^{5}$

Berdasarkan jenis kelamin, pasien terbanyak dengan kelompok jenis kelamin laki-laki yaitu 12 orang $(54 \%)$ dan kelompok jenis kelamin perempuan sebanyak 10 orang $(45,5 \%)$. Hasil ini sesuai dengan penelitian yang dilakukan oleh Susilo yang menunjukkan bahwa penderita infark miokard dengan jenis kelamin laki-laki sebanyak (16 orang) dan perempuan sebanyak (4 orang) pada tahun 2015 di RSD DR. Soebandi Jember. ${ }^{6}$ Hasil yang sama disebabkan karena laki-laki merupakan faktor resiko terbesar dibandingkan perempuan. Sesuai dengan teori mengenai jenis kelamin, dimana lakilaki lebih tinggi dari perempuan sebelum menopause akibat dari perlindungan estrogen yang bersifat protective pada perempuan namun setelah menopause insidensi penyakit jantung koroner meningkat dengan cepat dan sebanding dengan insidens pada laki-laki dengan usia terbanyak ada pada kelompok usia 56-66 tahun sebanyak 9 orang $(40,9 \%)$. Hal ini sesuai dengan penelitian yang dilakukan oleh Zainal ${ }^{7}$ yang mendapatkan kelompok usia 56-65 tahun merupakan kelompok usia terbanyak. Hasil penelitian yang dilaporkan oleh American Heart Association pada tahun 1994 mengenai hubungan antara jenis kelamin dan umur sebagai faktor resiko penyakit kardiovaskuler yang dikaitkan dengan penyakit jantung koroner diungkapkan bahwa pada kedua kelompok jenis kelamin, peningkatan risiko penyakit jantung koroner makin bertambah seiring pertambahan usia seseorang. ${ }^{8}$

Berdasarkan faktor risiko, yang terbanyak ialah dengan riwayat faktor resiko kombinasi yaitu sebanyak 13 orang $(59,1 \%)$. Hal ini sesuai dengan penelitian yang dilakukan oleh Zainal ${ }^{8}$ tahun 2008 yaitu distribusi penderita penyakit jantung koroner menurut jumlah faktor risiko diperoleh yang paling banyak adalah yang memiliki 4 faktor risiko yaitu 40 kasus (30, 3\%). Hal ini karena PJK merupakan penyakit multifaktorial. $^{9}$

Berdasarkan lokasi infark, didapatkan inferior ialah lokasi infark terbanyak yaitu $45 \%$. Hal ini sesuai dengan penelitian 
Antono yang mendapatkan infark inferior sebanyak $30-50 \%$ kasus, dan infark anterior sebanyak $10 \%$ kasus. $^{9}$

Berdasarkan nilai fraksi ejeksi, didapatkan hasil terbanyak pada fraksi ejeksi $\leq 40 \quad(45,5 \%)$, diikuti oleh nilai $\geq 54 \%$. Hal ini sesuai dengan hasil penelitian Patricia ${ }^{10}$ di RSUP Prof. Kandou Manado tahun 2012 yaitu jumlah sampel terbanyak dengan nilai fraksi ejeksi 30-39 $\%$ yaitu sebanyak 12 orang.

Berdasarkan jenis kelainan katup dilihat dari lokasi infark pada pasien nstemi, didapatkan jenis kelainan katup terbanyak yaitu kombinasi sebanyak 9 kasus (100\%); MR+PR (3), MR+PR+TR (3), MR+TR (1), AR+TR (1), AR+MR (1) yang terjadi pada infark inferior. Dalam European Journal of Cardiology, dikatakan bahwa infark inferior menyebabkan kelainan katup kombinasi yaitu MR dan TR, dengan adanya ruptur chordae tendinea menyebabkan regurgitasi katup mitral, akibatnya terjadi penurunan COP (Cardiac Output) karena darah yang dipompa dari ventrikel menuju katup aorta kembali ke atrium kiri, akibatnya jantung melakukan reaksi kompensasi untuk meningkatkan kontraktilitas dari ventrikel kiri agar dapat memompa darah yang mengandung $\mathrm{O}_{2}$ demi memenuhi kebutuhan otot jantung, namun tidak seimbang dengan pasokan $\mathrm{O}_{2}$ akibat sumbatan parsial maupun total di arteri koroner kanan, dengan demikian ventrikel kiri mengalami hipertrofi yang mengakibatkan peningkatan tekanan di ventrikel dan atrium kiri. Hal ini menyebabkan penimbunan cairan di paruparu (pulmonary hyperthension)yang berakibat pada peningkatan tekanan pada ventrikel kanan yang berujung pada dilatasi dan regurgitasi trikuspid. Hal ini juga merupakan indikasi terjadinya regurgitasi pulmonal. Sesuai dengan hasil penelitian, yaitu didapatkan sebanyak 9 orang $(100 \%)$ mengalami kelainan katup kombinasi dengan lokasi infark inferior pada pasien NSTEMI. ${ }^{11}$

Berdasarkan derajat beratnya kelainan katup dilihat dari lokasi infark pada pasien nstemi, didapatkan kasus terbanyak ialah kombinasi; MR mild yaitu sebanyak 5 kasus $(55,6 \%)$ PR mild sebanyak 5 kasus $(55,6 \%)$ dan TR mild sebanyak 3 kasus $(33,3 \%)$ pada infark inferior. Berdasarkan hasil penelitian oleh Grasso, yaitu ditemukan 13-45 \% kasus infark miokard inferior mengalami MR dengan derajat mild. Peningkatan tekanan $>20 \mathrm{mmHg}$ pada ventrikel kiri akan menyebabkan kongesti pulmonal yang berujung pada peningkatan tekanan dan dilatasi dari di ventrikel kanan yang bisa menyebabkan tricuspid regurgitasi dan pulmonal regurgitasi. Hal ini menunjang hasil penelitian yaitu didapatkan mr mild, tr mild dan pr mild pada infark inferior. ${ }^{12}$

\section{SIMPULAN}

Berdasarkan hasil penelitian, kasus tertinggi ialah NSTEMI yang didominasi oleh lokasi infark inferior dengan kelainan katup kombinasi yang memiliki derajat ringan (MR mild, PR mild, TR mild). Sebagian besar berjenis kelamin laki-laki, dengan umur terbanyak antara 56-66 tahun, dan faktor risiko terbanyak kombinasi 4 faktor resiko mayor.

\section{DAFTAR PUSTAKA}

1. Perhimpunan Dokter Spesialis Kardiovaskular Indonesia. Pedoman Tatalaksana Sindrom Koroner Akut (3rd ed). Jakarta: Centra Communications, 2015; p. 1-3.

2. Thaler MS. Buku EKG (7th ed). Jakarta: EGC, 2013; p. 222.

3. World Health Organization. The top ten causes of death. 2008. [cited 23 September 2013]. Available from: http://www.who.int/mediacentre/factsh eets/fs310_2008.pdf [

4. O'Gara PT, Frederick G. Kushner FG, et al. $2013 \mathrm{ACCF} / \mathrm{AHA}$ Guideline for the management of ST-Elevation myocardial infarction: A report of the American College of Cardiology Foundation/American Heart Association Task Force on Practice Guidelines. J Am Coll Card. 2013;12:;e362-e425.

5. Gabriel S, Stefan K, Luigi $P$, et al. ESC Guidelines for the management of acute myocardial infarction in patients 
presenting with ST- segment elevation. E Heart J. 2012;33:2569- 619.

6. Susilo C. Identifikasi faktor usia, jenis kelamin dengan luas infark miokard pada penyakit jantung koroner (PJK) di ruang ICCU RSD DR. Soebandi Jember. Indonesian J. 2015;6:3-4.

7. Zainal A. Faktor resiko penyakit jantung koroner pada pasien rawat inap di Cardiovaskular Care Unit (CVCU) Cardiac Centre di RSUP DR. Wahidin Sudiro Husodo Makasar Periode Januari-Juli 2008 [Skripsi]. Makassar: Universitas Hasanuddin; 2012.

8. Thygesen K, Joseph S, Alpert et al. Third universal definition of myocardial infarction. American Heart Assosiaction J. 2012;126:2020-35.
9. Nababan D. Hubungan faktor resiko dan karakteristik penderita dengan kejadian penyakit jantung koroner di RSUP DR. PIRNGADI Medan [Tesis]. Medan: Universitas Sumatera Utara; 2008.

10. Patricia. Hubungan kelas NYHA dengan fraksi ejeksi pada pasien gagal jantung kronik. RSUP Prof Dr R.D Kandou Manado. eCl. 2013;1(2).

11. Lancellotti P, Moura L, Pierard LA, Agricola E, Popescu BA, Tribouilloy C, et al. Mitral and tricuspid regurgitation. E Heart J. 2010;11:30732.

12. Wilansky S, Moreno CA, Lester SJ. Complication of Acute Myocardial Infarction. Crit Care Med. 2007;35(8):S348-54. 